УДК 621.039.5; 621.438

\title{
ВЛИЯНИЕ РАЗЛИЧНЫХ СПОСОБОВ ИНТЕНСИФИКАЦИИ ТЕПЛООБМЕНА В ТЕПЛООБМЕННОМ АППАРАТЕ НА ХАРАКТЕРИСТИКИ ВОЗДУШНОЙ ТЕПЛОУТИЛИЗИРУЮЩЕЙ ТУРБИННОЙ УСТАНОВКИ
}

Халатов А.А., академик НАН Украины, Северин С.Д., канд. техн. наук, Коваленко Г.В., канд. техн. наук, Мейрис А.Ж.

Институт технической теплофизики НАН Украины, ул. Желябова, 2а, Киев, 03580, Украина

\begin{abstract}
Виконано аналіз впливу перспективних способів інтенсифікації теплообміну в трубчастих теплообмінниках на їх теплову і гідравлічну ефективність, а також на ефективність ВТТУ в цілому. Представлено порівняння теплогідравлічних і масогабаритних характеристик теплообмінних апаратів 3 різноманітними способами внутрішньої та зовнішньої інтенсифікації теплообміну.
\end{abstract}

Выполнен анализ влияния перспективных способов интенсификации теплообмена в трубчатых теплообменниках на их тепловую и гидравлическую эффективность, а также на эффективность ВТТУ в целом. Представлено сравнение теплогидравлических и массогабаритных характеристик TOA с различными способами внутренней и внешней интенсификации теплообмена.
The analysis of the influence of the advance methods of heat transfer enhancement in tubular heat exchangers and their thermal hydraulic efficiency, as well as the efficiency of the whole air turbine waste heat recovery power plant are performed. Comparing of the heat exchanger thermal-hydraulic and weight and size characteristics with different ways of ducts internal and external heat transfer enhancement are represented.

Библ. 6, рис. 8.

Ключевые слова: воздушная теплоутилизирующая турбинная установка, теплообменные аппараты, интенсификация теплообмена, теплоотдача и гидравлическое сопротивление, теплогидравлическая эффективность.

$\mathrm{Re}_{\mathrm{d}}$ - число Рейнольдса, определённое по среднерасходной скорости и внутреннему диаметру трубы;

$\mathrm{Nu}_{\mathrm{d}}$ - число Нуссельта;

$\mathrm{Nu}_{\mathrm{d}} / \mathrm{Nu}_{\mathrm{d} 0}$ - фактор интенсификации теплоотдачи; $\zeta / \zeta_{0}-$ фактор увеличения гидравлического сопротивления;

$d$ - диаметр трубы (углубления);

$S_{1}$ - поперечный шаг труб в трубном пучке;

$S_{2}$ - продольный шаг труб в трубном пучке;

$t_{s c}$ - шаг накатки (выступов);

$h$ - высота цилиндрических выступов, удельная

энтальпия;

$Q$ - тепловая мощность теплообменного аппарата;

$G$ - массовый расход теплоносителя;

$N$ - мощность, затрачиваемая на прокачку теплоносителей;

$P$ - давление;

$T$ - температура; $\rho-$ плотность;

$\eta$ - коэффициент полезного действия.

\section{Сокращения:}

ГТС - газотранспортная система;

ГТУ - газотурбинная установка;

КПД - коэффициент полезного действия;

ИТТФ НАНУ - Институт технической теплофизики Национальной академии наук Украины;

ВТТУ - воздушная теплоутилизирующая турбинная установка;

ГТД - газотурбинный двигатель;

TOA - теплообменный аппарат.

\section{Индексы:}

0 - гладкая труба;

вн - внутренний;

нар - наружный;

вс - выступ. 
При эксплуатации ГТД со средним для ГТС Украины значением КПД 25 \% в окружающую среду с выходящими газами выбрасывается $75 \%$ первичной тепловой энергии топливного газа. Хотя современные жаростойкие материалы и методы охлаждения лопаток турбин позволяют использовать сравнительно высокие значения максимальной температуры цикла, тенденция к увеличению степени повышения давления в компрессоре ограничивает возможности применения регенерации теплоты в цикле. Другим вариантом повышения эффективности использования подводимой в цикле приводного ГТД теплоты является применение комбинированных теплоутилизационных циклов. Термодинамически выгодным было бы использование в качестве рабочего тела в утилизационном цикле воды и водяного пара, однако, традиции работников газотранспортных систем и перспективы полной их автоматизации заставляют оценивать возможности применения атмосферного воздуха в качестве теплоносителя для теплоутилизирующего цикла. Отсюда вытекает актуальность исследования газовоздушного теплообменника ограниченного веса и размеров.

Разработанные авторами математические модели ВТТУ и кожухотрубного теплообменного аппарата (ТОА), позволили выполнить анализ теплогидравлических характеристик теплообменного аппарата, являющегося составной частью перспективной ВТТУ. Для этого в данной работе выполнена серия сравнительных расчётов теплообменника с обычными гладкими трубами и с трубами с интенсификаторами теплообмена. Расчет выполнен для различных значений диаметров труб.

Предполагается, что в теплообменном аппарате горячая среда (продукты сгорания природного газа в воздухе) в межтрубном пространстве омывает пучок поперечно, а нагреваемый воздух, протекает внутри труб. Компоновка трубного пучка - шахматная или коридорная.

Для расчета теплообменного аппарата задаются: наружный диаметр труб $D_{H}$; внутренний диаметр труб $D_{B}$; шаг размещения труб по потоку $S_{2}$; поперечный шаг $S_{1}$; расход горячего газа $G_{\Gamma} ;$ температура горячего газа на входе в теплообменник $T_{\Gamma}^{\prime}$; давление горячего газа на входе $p_{\Gamma}^{\prime}$; коэффициент потерь давления по горячей стороне $\sigma_{\Gamma}$; расход воздуха $G_{X}$; температура воздуха на входе $T_{X}^{\prime}$; температура воздуха на выходе $T_{X}^{\prime \prime}$; давление воздуха на входе $p_{X}^{\prime}$; число ходов по горячей $n_{\Gamma}$ и по холодной $n_{X}$ сторонам.

В результате расчета ТОА определяются: коэффициенты теплоотдачи по горячей и холодной сторонам, коэффициент теплопередачи, потребная поверхность теплообмена, площади проходных сечений по горячей и холодной сторонам, габаритные размеры теплообменника, а также коэффициенты потерь давления в горячем и холодном трактах.

Целью второй части расчета является определение рациональных параметров теплообменника. При расчете вариантов могут изменяться:

1) продольный и поперечный шаги размещения труб;

2) число ходов по горячей и холодной сторонам;

3) соотношения между коэффициентами потерь давления;

4) наружный и внутренний диаметры труб;

5) способы интенсификации теплообмена в трубах.

Для оценки эффективности ТОА используется гидравлический и полный КПД теплообменника.

Так, степень совершенства ТОА, с точки зрения затрат энергии на перемещение теплоносителей через его горячий и холодный тракты, характеризуется гидравлическим КПД, который определялся следующим выражением:

$\eta_{\text {гидр }}=\frac{Q-\sum N_{n}}{Q}$,

где $Q=G_{x}\left(h_{x}^{6 ы x}-h_{x}^{6 x}\right)-$ тепловая мощность теплообменного аппарата, определяемая по параметрам вторичного (холодного) теплоносителя. Здесь $h_{x}^{\text {выx }}$ и $h_{x}^{6 x}-$ соответственно энтальпии холодного теплоносителя на выходе и входе теплообменника.

$\Sigma N_{n}$ - суммарная мощность, затрачиваемая на прокачку теплоносителей через ТОА. Очевидно, что при $\Sigma N_{n} \rightarrow 0 \eta_{\text {гидр }} \rightarrow 1$. Суммарная 
мощность, затрачиваемая на преодоление гидравлических сопротивлений при перемещении теплоносителей через ТОА без учёта диссипации, определяется выражением:

$\sum N_{n}=\frac{G_{2} \Delta P_{2}}{\bar{\rho}_{z}}+\frac{G_{x} \Delta P_{x}}{\bar{\rho}_{x}}$,

где $\bar{\rho}_{z}$ и $\bar{\rho}_{x}$ - средние значения плотности теплоносителей в горячем и холодном трактах; $\Delta P_{2}, \Delta P_{x}-$ абсолютные значения потерь давления в горяхчем и холодном трактах.

Полный КПД теплообменного аппарата является показателем его тепловой и гидравлической эффективности. Он характеризует потери теплоты с уходящим первичным (горячим) теплоносителем и затраты энергии на прокачку теплоносителей через ТОА. Поэтому при его определении необходимо из тепловой мощности ТОА вычесть тепловую мощность, эквивалентную мощности, затраченной на прокачку теплоносителей в аппарате, а затем полученную разность отнести к располагаемой тепловой мощности $\left(Q_{p}\right)$. Таким образом, полный КПД теплообменного аппарата определяется следующим выражением:

$$
\eta_{\text {тоA }}=\frac{Q-\sum N_{n}}{Q_{p}}
$$

Выполнив несложные преобразования, можно показать, что полный КПД ТОА представляет собой произведение его тепловой эффективности (теплового КПД) и его гидравлического КПД:

$$
\eta_{\text {TOA }}=\eta_{m} \eta_{\text {гидр }} \text {. }
$$

Оптимизация ТОА может производиться по минимуму массы или объема аппарата или по максимуму полного КПД ТОА. Наиболее предпочтительная расчётная схема трубчатого теплообменника с точки зрения оценки гидравлических потерь представлена на рисунке 1.

Были исследованы три перспективных способа интенсификации теплообмена в круглых трубах на эффективность теплообменного аппарата и эффективность ВТТУ. Эти интенсификаторы являются технологичными и недорогими в промышленном производстве. Были проанализированы следующие варианты трубчатых теплообменных поверхностей (рис. 2):

1. Круглые трубы с цилиндрической накаткой (диафрагмы) [1, 2] (рис. 2, a).

2. Круглые трубы с винтовой накаткой $[2,5]$ (рис. 2, б).

3. Круглые трубы со сферическими углублениями (выступами внутри) [3] (рис. 2, в).

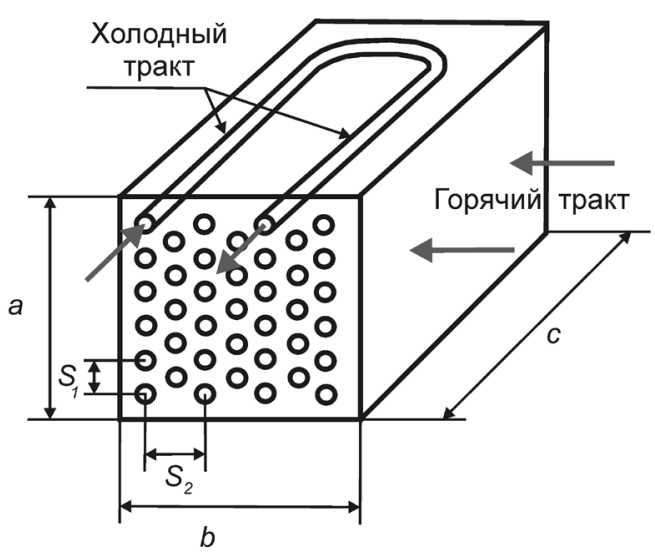

Рис. 1. Расчётная схема трубчатого теплообменника с одним «проходом" по горячему тракту и двумя "проходами» по холодному тракту.

Для труб с цилиндрической и винтовой накаткой факторы интенсификации теплообмена и увеличения гидравлического сопротивления рассчитывались по известным зависимостям, приведенным в работах $[1,2,5]$.

Для исследованных в ИТТФ НАНУ круглых труб со сферическими углублениями (выступами) (рис. 2, в) были получены и использованы в математической модели ТОА корреляционные зависимости для интенсификации теплообмена при течении теплоносителя внутри труб. Так для относительной величины продольного и поперечного шагов углублений находящихся в диапазоне $t_{I} / d\left(t_{2} / d\right)=0,26 \ldots 3,37$ (рис. 2, в), относительной высоты выступов $h_{\text {вс }} / d_{\text {вс }}=0,055 \ldots 0,0663$ и для диапазона изменения чисел Рейнольдса в трубах $\mathrm{Re}_{d}=5000 \ldots 40000$ :

$$
\frac{N u_{d}}{N u_{d 0}}=\frac{1}{N u_{d 0}} A \operatorname{Re}_{d}^{B}
$$

где $A=-0,46+11,1\left(\frac{h_{\theta c}}{d_{\theta H}}\right) ; B=1,02-7\left(\frac{h_{\theta c}}{d_{\theta H}}\right)$,

где $h_{в c}-$ высота сферических выступов; 


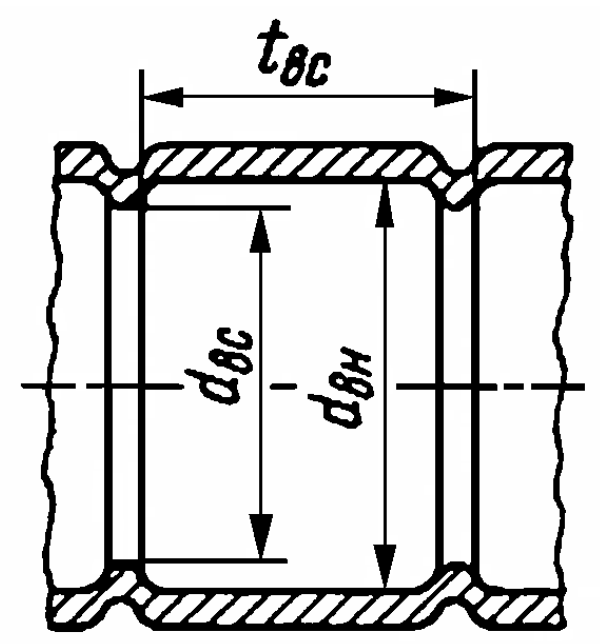

a)

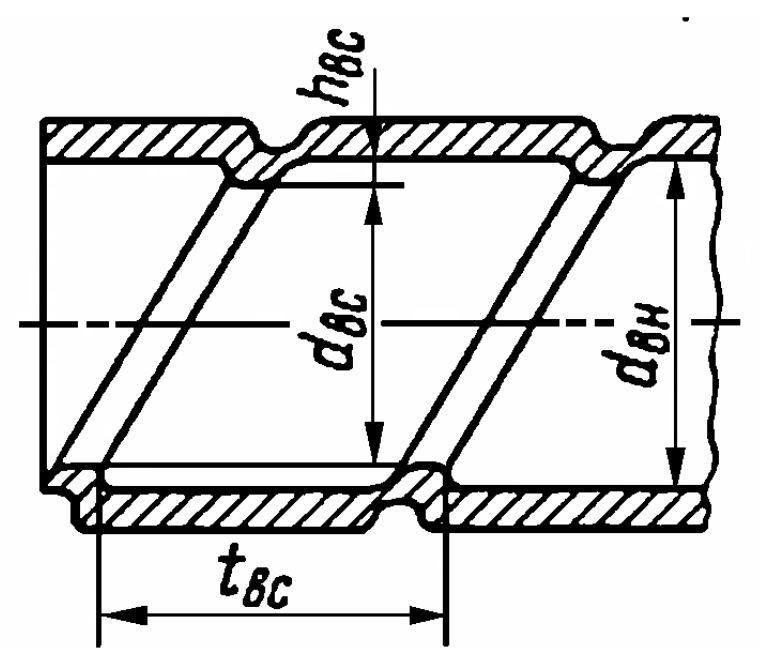

б)

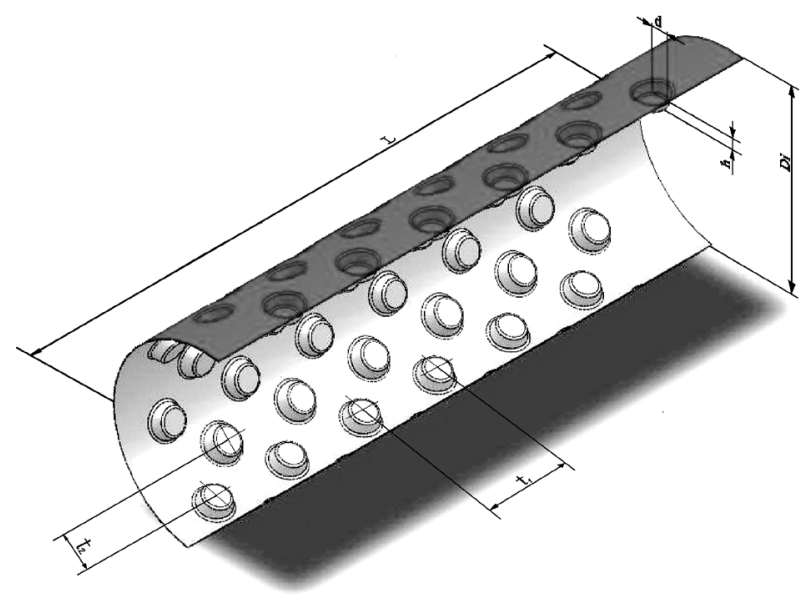

Рис. 2. Исследованные способы интенсификации теплообмена в круглых трубах.

$d_{\text {вн }}$ - внутренний диаметр труб.

Здесь значение числа $N u_{d 0}$ для гладкой трубы определялось на основе известной зависимости Диттуса-Болтера:

$$
N u_{d 0}=0,023 \operatorname{Re}_{d}^{0,8} \operatorname{Pr}^{0,4} .
$$

Для фактора увеличения коэффициента потерь при течении теплоносителя в трубах со сферическими углублениями (выступами) авторами предложена следующая экспериментальная корреляционная зависимость:

$$
\xi / \xi_{0}=52,56 \mathrm{Re}_{d}^{-0,36} \text {. }
$$

Для фактора интенсификации теплообмена и фактора увеличения гидравлического сопротивления со стороны горячего теплоносителя (внешняя часть труб), согласно рекомендациям работы [6], были приняты следующие значения $N u_{d} / N u_{d 0}=1,15$ и $\zeta / \zeta_{0}=1,15$ соответственно.

Исследования были выполнены для поперечного и продольного относительного шагов труб в трубном пучке $S_{1} / d_{\text {нар }}=2,5 ; S_{2} / d_{\text {нар }}=2,5$ $\left(d_{\text {нар }}=0,03 \mathrm{~m} ; d_{g h}=0,027 \mathrm{м}\right)$ и для геометрических параметров интенсификаторов теплообмена представленных в таблице 1.

На рисунках 3 и 4 представлены зависимости гидравлического и полного КПД теплообменника ВТТУ от расхода воздуха через ВТТУ для трёх способов интенсификации теплообмена в трубах TOА. Из анализа приведенных зависимостей видно, что использование труб с цилиндрической накаткой и труб с винтовой накаткой приводит к снижению гидравлического КПД теплообменного аппарата во всём 
исследованном диапазоне изменения расхода воздуха вторичного теплоносителя. Это обусловлено ростом гидравлических потерь в горячем и холодном трактах ТОА. Использование круглых труб со сферическими углублениями приводит к незначительному увеличению гидравлического и полного КПД теплообмен- ного аппарата в диапазоне изменения расхода воздуха через ВТТУ $45 \leq G_{6} \leq 52,5$ кг/с и к незначительному снижению гидравлического и полного КПД ТОА в диапазоне изменения расхода воздуха через ВТТУ в диапазоне $60 \leq G_{в} \leq 75$ кг/с. Так в расчётной точке $\left(G_{6}=65^{6}\right.$ кг/с) гидравлический КПД ТОА ВТТУ

Таблица 1

\begin{tabular}{|l|c|c|c|c|}
\hline \multicolumn{1}{|c|}{ Тип интесификатора } & $d_{B c} / d_{\theta H}$ & $t / d_{\theta H}$ & $t / d_{y z л}, M$ & $d_{y z л}, M$ \\
\hline Цилиндрическая накатка (диафрагмы) & 0,98 & 0,5 & - & - \\
\hline Винтовая накатка & 0,98 & 0,5 & - & - \\
\hline Сферические углубления (выступы) & 0,87 & 0,06 & 1,63 & 0,0034 \\
\hline
\end{tabular}

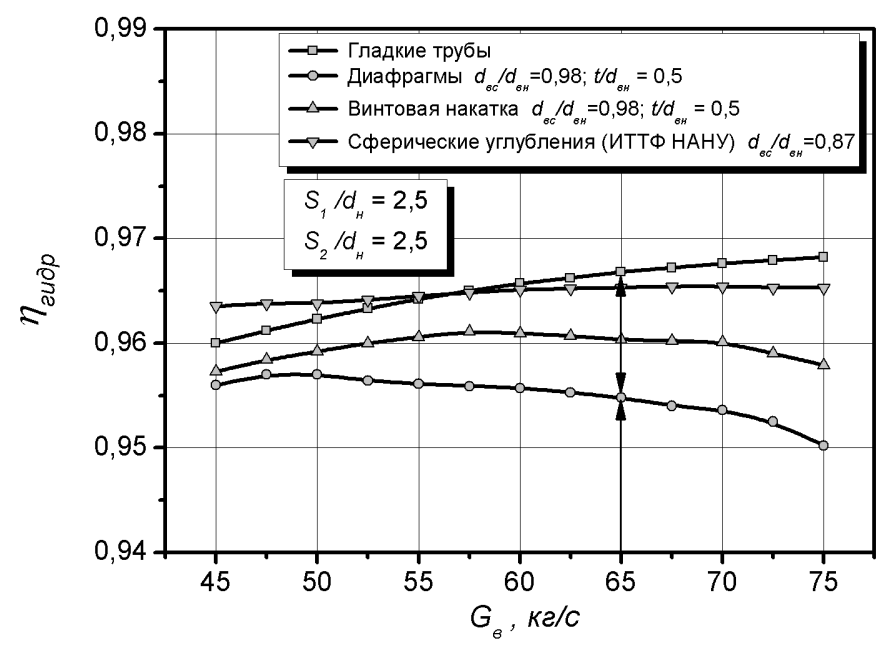

Рис. 3. Зависимость гидравлического КПД теплообменника ВТТУ от расхода воздуха через ВТТУ для различных способов интенсификации теплообмена в трубах ТОА.

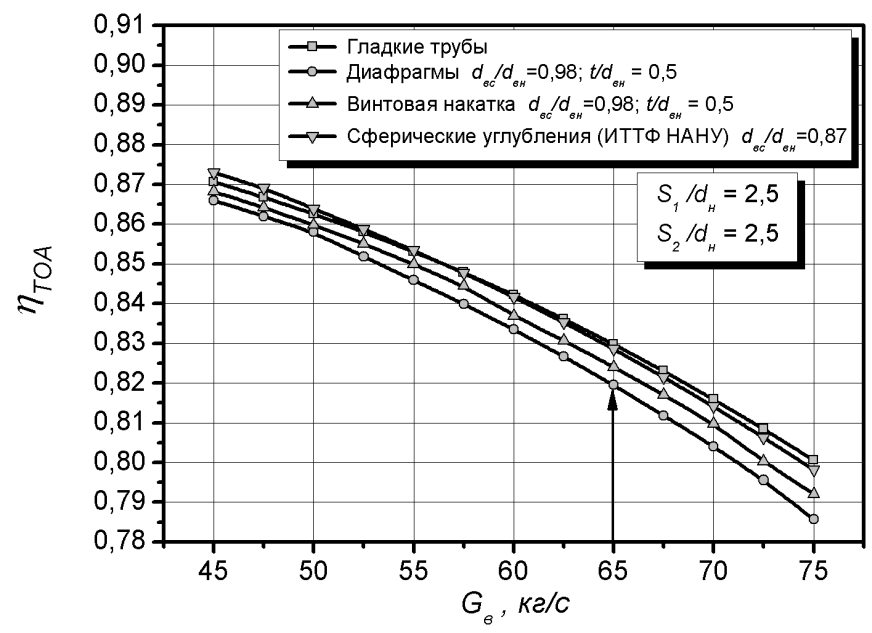

Рис. 4. Зависимость полного КПД теплообменника ВТТУ от расхода воздуха через ВТТУ для различных способов интенсификации теплообмена в трубах ТОА. 
снижается на 0,16 \% при использовании труб со сферическими углублениями, на 1,3 \% при использовании труб с диафрагмами и на 0,96 \% при использовании труб с винтовой накаткой. В выбранной расчётной точке $\left(G_{k}=65\right.$ кг/с) использование интенсификации теплообмена приводит к снижению полного КПД теплообменного аппарата на 0,25 \% при использовании труб со сферическими углублениями, на 1,2 \% при использовании труб с диафрагмами и на 0,72 \% при использовании труб с винтовой накаткой.

На рисунках 5 и 6 представлены зависимости массы поверхностей теплообмена теплооб- менника ВТТУ и его объёма от расхода воздуха через ВТТУ для различных способов интенсификации теплообмена в трубах кожухотрубного ТОА. Из анализа представленных зависимостей следует, что при использовании в качестве интенсификаторов теплообмена круглых труб с диафрагмами и спиральной накаткой масса поверхностей теплообмена ТОА ВТТУ снижается в расчётной точке на $67 \%$, а при использовании труб со сферическими углублениями - на 24 \%. При этом, объём теплообменника в первых двух случаях снижается на 73 \%, а во втором - на $30 \%$.

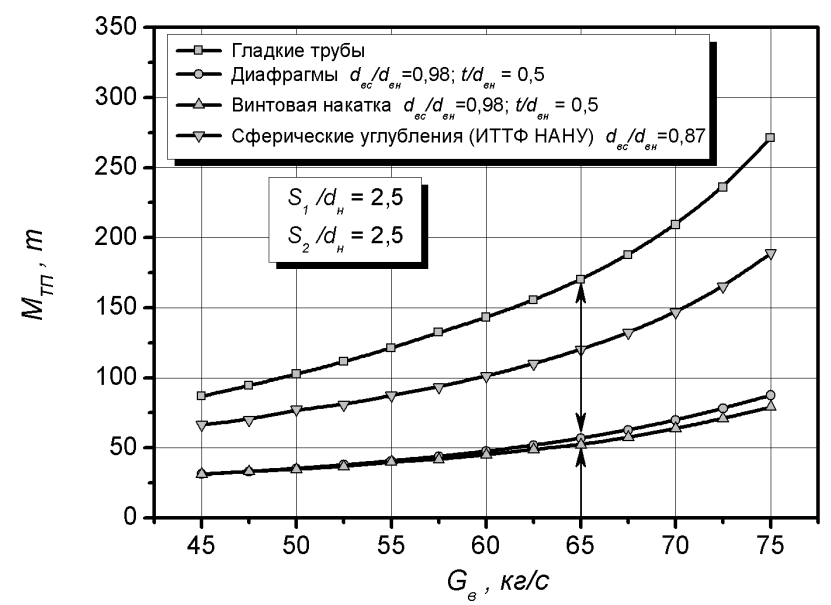

Рис. 5. Зависимость массы поверхностей теплообмена теплообменника ВТТУ от расхода воздуха через ВТТУ для различных способов интенсификации теплообмена в трубах ТОА.

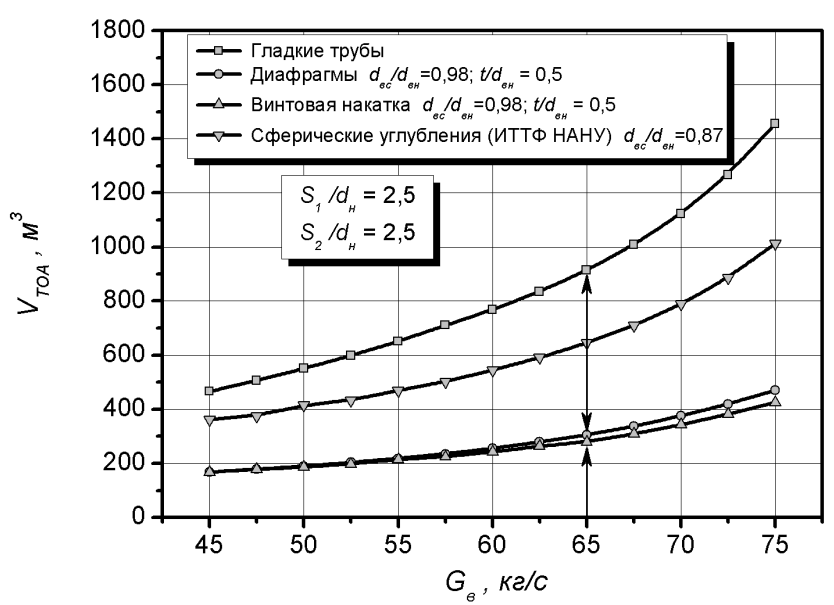

Рис. 6. Зависимость объёма теплообменника ВТТУ от расхода воздуха через ВТТУ для различных способов интенсификации теплообмена в трубах ТОА. 


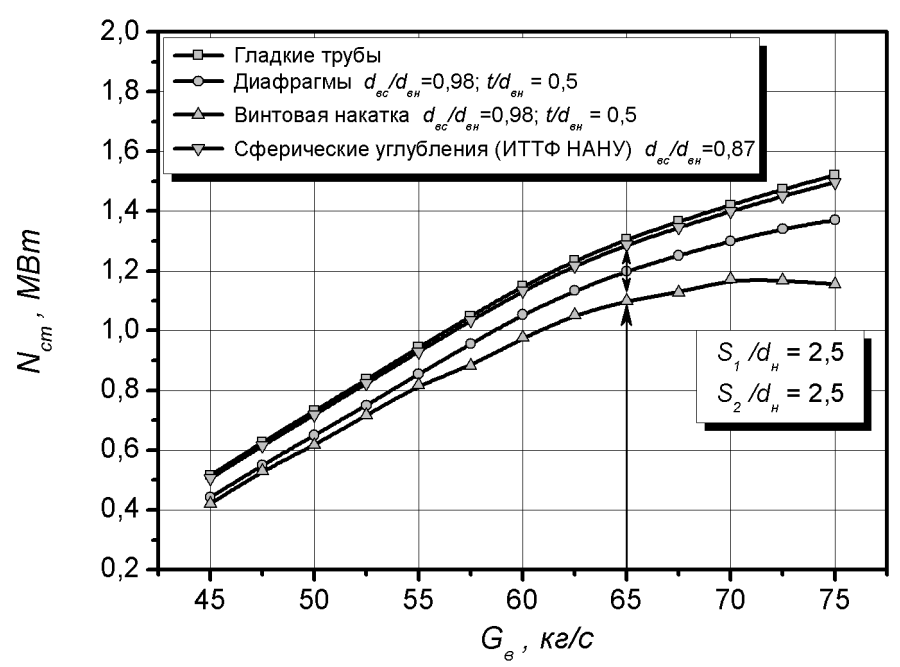

Рис. 7. Зависимость мощцости силовой мурбины ВТТУ от расхода воздуха через ВТТУ для различных способов интенсификации теплообмена в трубах ТОА.

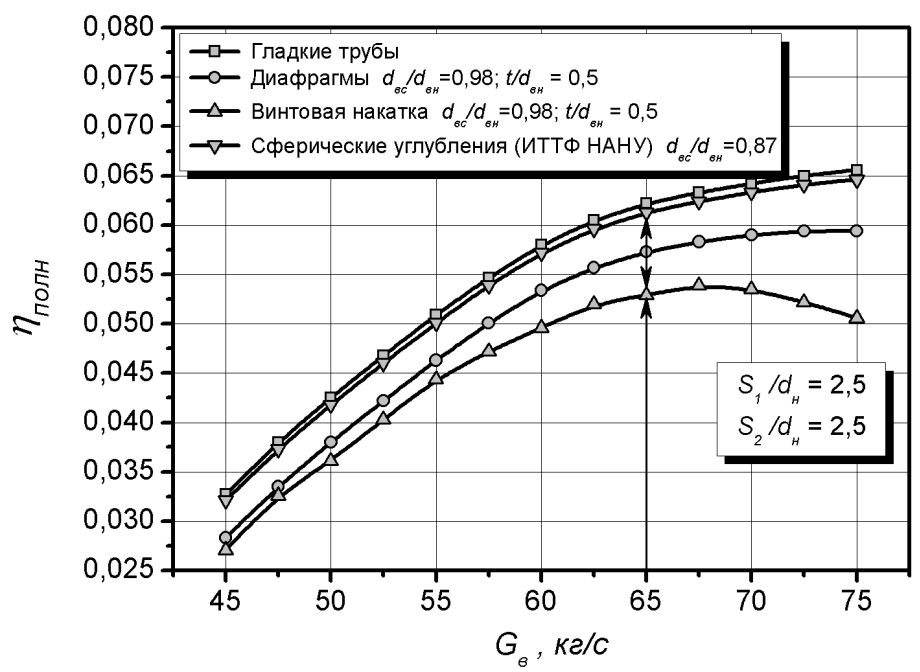

Рис. 8. Зависимость полного КПД ВТТУ от расхода воздуха через ВТТУ для различных способов интенсификации теплообмена в трубах ТОА.

Расчётное исследование мощностных и экономических характеристик ВТТУ было выполнено для ВТТУ мощностью 1,3 МВт установленной на выходе из энергетической ГТУ типа ДН-80 мощностью 25 МВт (ГП НПКБ «Зоря Машпроект») с расходом газов на выходе $-87,5$ кг/с и температурой $-480{ }^{\circ} \mathrm{C}$.

На рисунках 7, 8 представлены зависимости мощности силовой турбины (электрической мощности) ВТТУ и полного КПД ВТТУ от расхода воздуха через ВТТУ для различных способов интенсификации теплообмена в тру- бах ТОА. Из анализа приведенных на рис. 7 и 8 зависимостей следует, что использование интенсификации теплообмена в трубах теплообменного аппарата приводит к снижению полезной мощности и полного КПД ВТТУ за счет роста гидравлических потерь.

Как следует, в выбранной расчётной точке, соответствующей значению расхода воздуха через ВТТУ $G_{\theta}=65$ кг/с, мощность силовой турбины снижается на 1,6 \% при использовании труб со сферическими углублениями, на 4,8 \% - при использовании труб с диафрагма- 
ми и на 16,7 \% при использовании труб с винтовой накаткой. При этом полный КПД ВТТУ снижается на 0,65 \% при использовании труб со сферическими углублениями, на 7,8 \% при использовании труб с диафрагмами и на $16 \%$ при использовании труб с винтовой накаткой.

\section{Выводы}

Анализ состояния и исследование потенциальных возможностей уменьшения выброса теплоты с выходящими продуктами сгорания ГТП украинской ГТС показал:

1. Доступным и малозатратным методом использования теплоты выходящих газов у современных ГТД является её утилизация в бинарном цикле комбинированной установки с BTTУ.

2. Применение воздушной утилизации теплоты позволяет существенно (на 14...17 \%) уменьшить количество теплоты, выбрасываемой из основной ГТУ, что позволяет для установок на базе современных ГТД простой схемы получить коэффициент использования теплоты $42 . .47 \%$.

3. Наиболее эффективными способами интенсификации теплообмена из трёх рассмотренных с точки зрения снижения объёма и массы теплообменного аппарата является использование цилиндрических труб с диафрагмами или труб с винтовыми накатками, которые позволяют уменьшить объём ТОА в расчётной точке на $72 \ldots 73 \%$, и массу - на $67 \%$ при снижении мощности ВТТУ на 4,8 \% и $16 \%$ соответственно.

4. Исследованный в ИТТФ НАНУ способ интенсификации теплообмена с использованием труб со сферическими выступами - углублениями позволяет уменьшить объём ТОА в расчётной точке на $30 \%$ и массу - на $24 \%$, при снижении мощности ВТТУ всего на 1,6 \%.

5. При проектировании теплообменного аппарата ВТТУ с интенсификацией теплообмена целесообразно использование труб с винтовыми накатками или с диафрагмами в том случае, когда определяющим критерием проектирования является минимальная масса и объем ТОА и труб со сферическими выступами-углублениями, для обеспечения высокой мощности ВТТУ.

\section{ЛИТЕРАТУРА}

1. Калинин Э.К., Дрейцер Г.А., Ярхо С.А. Интенсификация теплообмена в каналах. - М.: Машиностроение, I издание, 1972, II издание, 1981.

2. Справочник по теплообменникам / П.И. Бажан, Г.Е. Каневец, В.М. Селивестров. - М.: Машиностроение, 1989. - 366 с.

3. Халатов А.А., Коваленко Г.В., Северин С.Д., Бурлака В.В., Мейрис А.Ж. Применение теплообменных поверхностей типа «углубление-выступ» в теплообменниках газотурбинных установок // Промышленная теплотехника. - 2014. - T. 36, №5. - С. $34-45$.

4. Коваленко Л.М., Глушков А.Ф. Теплообменники с интенсификацией теплоотдачи. М.: Энергоатомиздат, 1986. - 249 с.

5. Обобщение данных по гидравлическому сопротивлению в винтообразных профилированных трубах / Ю.Н. Боголюбов, Ю.М. Бродов, В.Т. Буглаев и др. // Изв. Вузов. Энергетика. 1980. №4. С. $71-73$.

6. Теплообмен в элементах конструкции двигателей ЛА / Под редакцией Г.А. Дрейцера, В.П. Солнцева, М., Изд. МАИ, 1989, 49 с. 


\section{INFLUENCE OF DIFFERENT METHODS OF HEAT TRANSFER ENHANSMENT IN HEAT EXCHANGER ON AIR TURBINE WAIST HEAT RECOVERY POWER PLANT HARACTERISTICS}

\section{Khalatov A.A., Severin S.D., Kovalenko G.V., Meyris A.J.}

Institute of Engineering Thermophysics of the National Academy of Sciences of Ukraine, 2a Zhelyabova St, Kyiv, 03680, Ukraine

The analysis of the influence of the advance methods of heattransferenhancement in tubularheat exchangers and their thermal hydraulic efficiency, as well as the efficiency of the whole air turbine waste heat recovery power plant are performed. Comparing of the heat exchanger thermalhydraulic and weight and size characteristics with different ways of ducts internal and external heat transfer enhancement are represented.

The got by author's correlations for the investigated before method of heat transfer enhancement in the tubular ducts of "cavity convex" type those was used in heat exchanger mathematic model are represented in the paper.

Application of air cycle waste heat recovery allows substantially (on $14.17 \%$ ) to decrease the amount of heat, thrown out from basic gas turbine power plant, that allows for power plants on the base of modern gas turbine engines of simple schemes to achieved the coefficient of the heat using value $42 . . .47 \%$.

It is shone that from three investigated methods of heat transfer enhancement considered from the point of decreasing the heat exchanger mass and volume the most effective method is the use of cylindrical ducts with diaphragms or ducts with spiral rolling-ups, which allows decrease air turbine waste heat recovery power plant on $73 \%$ and mass - on $67 \%$ at it's power decreasing on
4,8 \%. However investigated in Institute of Engineering Thermophysics of NANU method of heat transfer enhancement with the use of ducts with spherical cavities - convexes allows to decrease the volume of heat exchanger on 30 $\%$, and mass - on $24 \%$ at air turbine waste heat recovery power plant power decreasing only on $1,6 \%$.

\section{References 6, figures 8 .}

Key words: air turbine waist heat recovery power plant, heat exchangers, heat transfer enhancement, heat transfer and pressure drop, thermohydraulic effectiveness.

1. Kalinin E.K., Dreytser G.A., Yarkho S.A. Intensification of heat transfer in channels. - M.: Engineering, I - $\mathrm{t}$ edition, 1972, II $-\mathrm{d}$ edition, 1981.

2. Reference book on heat exchangers / P.I. Bazhan, G.E. Kanevets, V.M. Selivestrov. - M.: Engineering, 1989. - 366 p.

3. Khalatov A.A., Kovalenko G.V., Severin S.D., Burlaka V.V., Meyris A.J. Application of tubular heat transfer surfaces of "cavity - convex" type in gas turbine power plants heat exchangers. // Industrial heat engineering. - 2014. V. 36, №5. P. $34-45$.

4. Kovalenko L.M., Glushkov A.F. Heat exchangers with heat transfer enhancement. M.: Energoatomizdat, 1986. - 249 p.

5. Generalization of information on hydraulic resistance in the spiral profiled pipes / Yu.N. Bogolyubov, Yu.M. Brodov, V.T. Buglaev and other // Inf. of Institutes. Energetic. 1980. № 4. P. 71-73.

6. A heat transfer in the elements of construction of flying apparatus engines / under edition of G.A.Dreytser, V.P. Solntsev, M, Publ. MAI, 1989, 49 p. 